\title{
Feeding barley grain steeped in lactic acid modulates rumen fermentation patterns and increases milk fat content in dairy cows
}

\author{
S. Iqbal, ${ }^{\star}$ Q. Zebeli, ${ }^{*}$ A. Mazzolari, ${ }^{* 1}$ G. Bertoni,† S. M. Dunn, ${ }^{*}$ W. Z. Yang,‡ and B. N. Ametaj ${ }^{* 2}$ \\ ${ }^{*}$ Department of Agricultural, Food and Nutritional Science, University of Alberta, Edmonton, Alberta, Canada T6G 2P5 \\ †Istituto di Zootecnica, University Catolica di Sacro Cuore, Via Emilia Parmense 81, 29100 Piacenza, Italy \\ $\ddagger$ Research Centre, Agriculture and Agri-Food Canada, Lethbridge, Alberta, Canada T1J 4B1
}

\section{ABSTRACT}

The objectives of the present in vivo and in situ trials were to evaluate whether feeding barley grain steeped in lactic acid (LA) would affect rumen fermentation patterns, in situ dry matter (DM) degradation kinetics, and milk production and composition in lactating dairy cows. The in vivo trial involved 8 rumen-fistulated Holstein cows fed once daily a total mixed ration containing rolled barley grain (27\% in DM) steeped for $48 \mathrm{~h}$ in an equal quantity of tap water (CTR) or in $0.5 \%$ LA (TRT) in a $2 \times 2$ crossover design. The in situ trials consisted of incubation of untreated rolled barley grain in cows fed CTR or TRT diets and of incubation of 3 different substrates including CTR or barley grain steeped in $0.5 \%$ or $1.0 \%$ LA (TRT1 and TRT2, respectively) up to $72 \mathrm{~h}$ in the rumen. Results of the in vivo trial indicated that cows fed the TRT diet had greater rumen $\mathrm{pH}$ during most intensive fermentation phases at 10 and $12 \mathrm{~h}$ post-feeding. The latter effect was associated with a shorter duration in which rumen $\mathrm{pH}$ was below 5.8 for cows fed the TRT diet $(2.4 \mathrm{~h})$ compared with CTR diet $(3.9 \mathrm{~h})$. Furthermore, cows fed the TRT diet had lower concentrations of volatile fatty acids at 2 and $4 \mathrm{~h}$ post-feeding. In addition, concentrations of preprandial volatile fatty acids were lower in the rumen fluid of cows fed the TRT diet. Results also showed that molar proportion of acetate was lower, whereas propionate tended to increase by feeding cows the TRT diet. Cows fed the TRT diet demonstrated greater rumen in situ lag time of substrate DM degradation and a tendency to lower the fractional degradation rate. Other in situ results indicated a quadratic effect of LA on the effective rumen degradability of substrates whereby the latter variable was decreased from CTR to TRT1 but increased for TRT2 substrate. Although the diet did not affect actual milk yield, fat-corrected milk, percent-

Received May 13, 2009.

Accepted September 1, 2009.

${ }^{1}$ Current address: Pioneer Hi-Bred Italia, Via Pari Opportunita 2, 26030 Gadesco Pieve Delmona, Cremona, Italy.

${ }^{2}$ Corresponding author: burim.ametaj@ualberta.ca ages of milk protein, and lactose and concentration of milk urea nitrogen, cows fed the TRT diet increased milk fat content and tended to increase fat:protein ratio in the milk. In conclusion, results demonstrated that treatment of barley grain with LA lowered the risk of subacute rumen acidosis and maintained high milk fat content in late-lactating Holstein cows fed diets based on barley grain.

Key words: barley grain, lactic acid, dairy cow, rumen fermentation

\section{INTRODUCTION}

Lactating dairy cows require large amounts of dietary energy for maintenance, milk production, and reproduction. Barley grain is included in dairy cow rations in many regions of the world where this type of grain is a cost-effective digestible energy source. Yet, because barley grain contains starch that is rapidly fermentable in the rumen, its high inclusion in the diets of lactating cows is associated with accumulation of large amounts of fermentation acids and low $\mathrm{pH}$ of the rumen fluid (Yang et al., 1997; Emmanuel et al., 2008). Maintenance of rumen $\mathrm{pH}$ above 5.8 during the intensive fermentation processes is critical for the activity of microbiota and prevention of subacute rumen acidosis (SARA; Krause and Oetzel, 2006; Zebeli et al., 2008). Development of SARA is associated with impaired digestion, lowered nutrient utilization and milk fat content (Stone, 2004), and high incidence of metabolic disorders (Nocek, 1997; Ametaj et al., 2005).

The potential for high-grain diets to cause SARA can be alleviated by lowering the amount of rumen-fermentable starch contained in the concentrate mixture (Zebeli et al., 2008). The latter could be attained either by decreasing the amount of starch available for rumen degradation or by increasing the quantity of starch that bypasses degradation in the rumen. Several processing methods have been proposed over the years to modulate rumen degradability of readily degradable grains that contain starch. Some of those methods include mechanical or temperature processing techniques such 
as pelleting, roasting, and dry or steam rolling as well as chemical methods including treatment of grains with chemical agents like $\mathrm{NaOH}$, formaldehyde, ammonia, or fibrolytic enzymes (Dehghan-Banadaky et al., 2007). In order for a processing technology to be adopted by the dairy industry, it must be cost-effective, provide outcomes that justify its use, and be easily applied under farm conditions. In fact, the cost of mechanical and thermal processing continues to increase and requires additional investments, and some of the chemical agents used, like formaldehyde or $\mathrm{NaOH}$, are corrosive and pose health risks to laborers (Dehghan-Banadaky et al., 2007).

Recent in vitro and in vivo human studies have demonstrated that organic acids or their salts, such as sodium propionate and calcium lactate, modify the structure of starch molecules imparting resistance against amylolytic attack (Liljeberg et al., 1995). The mild organic acids lack corrosiveness and pose no health risks to the laborers. More importantly, lactic acid (LA) has been successfully used by the food industry to modify starch degradation. For example, treatment of dough with LA has been shown to lower the rate of starch digestion in human consumers by decreasing the rate of amylolysis (Östman et al., 2002). In addition, treatment of starch with LA increases starch recovery rates in corn grain by facilitating separation of starch granules from the protein matrix (Perez et al., 2001; Östman et al., 2002). Other reported beneficial effects of steeping cereals in LA solutions are lower rate of lipid oxidation (Rutgersson et al., 2000) and greater availability of minerals from the grain kernel (Manzoni et al., 2002).

To our best knowledge no previous investigations have been conducted in relation to the effects of steeping cereal grains in LA on the health and productivity of livestock animals. We hypothesized that treating rolled barley grain with LA might improve rumen fermentation patterns, increase milk fat production and overall productivity of dairy cows, and lower the risk of SARA by modulating starch degradation characteristics of barley grain. Therefore, we conducted an in vivo as well as an in situ trial aimed at evaluating the effects of rolled barley grain steeped in LA on rumen fermentation patterns, DM degradation kinetics, and milk production and composition in lactating dairy cows.

\section{MATERIALS AND METHODS}

\section{Animals and Diets}

All experimental procedures were approved by the University of Alberta Animal Care and Use Committee for Livestock, and animals were cared for in accordance with the guidelines of the Canadian Council on Animal
Care (1993). Veterinary supervision was provided to the animals throughout the experiment. Eight ruminally cannulated (100 mm i.d.; Bar Diamond, Parma, ID) primiparous Holstein cows were used in this experiment. Upon commencement of the experiment, the cows were at 198 to 236 DIM, had an average milk production of $28 \mathrm{~kg} / \mathrm{d}$, and weighed $680 \pm 30 \mathrm{~kg}$. The cows were assigned to 1 of the 2 dietary treatments according to a paired $2 \times 2$ crossover design with 2 study periods. Each experimental period was $21 \mathrm{~d}$, with the first $10 \mathrm{~d}$ used for adaptation to diets and $11 \mathrm{~d}$ for experimental measurements. Cows were offered a TMR containing (DM basis) $15 \%$ alfalfa hay, $40 \%$ barley silage, and $18 \%$ energy and protein supplement. In addition, 27\% (DM basis) rolled barley grain, steeped in an equal quantity (i.e., in a ratio of 1 to 1 , wt/vol) of either tap water alone (CTR) or of $0.5 \%$ LA solution (TRT), was added to the TMR just before the morning feeding. Dry matter content of untreated rolled barley grain was $85.4 \% \pm 1.25$ and decreased to $42.7 \% \pm 1.13$ and $43.1 \% \pm 1.32$ (mean \pm SD) after steeping it in tap water or $0.5 \% \mathrm{LA}$, respectively. The rolled barley was steeped for $48 \mathrm{~h}$ before being mixed into the TMR. The LA (DL-lactate, 85\%, wt/wt) used in this study was purchased from Sigma (Ontario, Canada). The diets were formulated to meet or exceed the requirements of a 680-kg lactating cow producing approximately $25 \mathrm{~kg}$ of milk/d with $3.5 \%$ fat as per NRC (2001) guidelines. The cows were fed for ad libitum intake to permit at least $5 \%$ orts. The cows were housed in individual tie stalls bedded with sawdust and had free access to water. Diets were fed once daily at $0800 \mathrm{~h}$.

Diet ingredients were dried in a $55^{\circ} \mathrm{C}$ forced-air oven for $72 \mathrm{~h}$ to determine DM content. The dried samples were ground through a 1-mm screen using a Wiley mill (Thomas-Wiley, Philadelphia, PA). Samples were analyzed for concentrations of DM, ash, NDF, ADF, $\mathrm{CP}$, and starch. The DM content was determined by drying samples at $135^{\circ} \mathrm{C}$ for $2 \mathrm{~h}$ (AOAC, 2002; method 930.15). Ash concentration was determined after $5 \mathrm{~h}$ at $550^{\circ} \mathrm{C}$ in a furnace (AOAC, 2002; method 942.05). Methods of Van Soest et al. (1991) were used in the analyses of NDF and ADF using heat-stable amylase and sodium sulfite in the case of NDF. Crude protein was quantified by flash combustion with gas chromatography and thermal conductivity detection (Carlo Erba Instruments, Milan, Italy). Barley grain starch content was determined using an enzymatic colorimetric method with EnzyChrom assay kit (BioAssay Systems, Hayward, CA). This is a 2-phase method to quantify the concentrations of both soluble and resistant starch (McCleary and Monaghan, 2002). All samples were tested in triplicate and the optical density values were read in a microplate spectrophotometer (Spectramax 
Table 1. Ingredients and chemical composition of the experimental diets

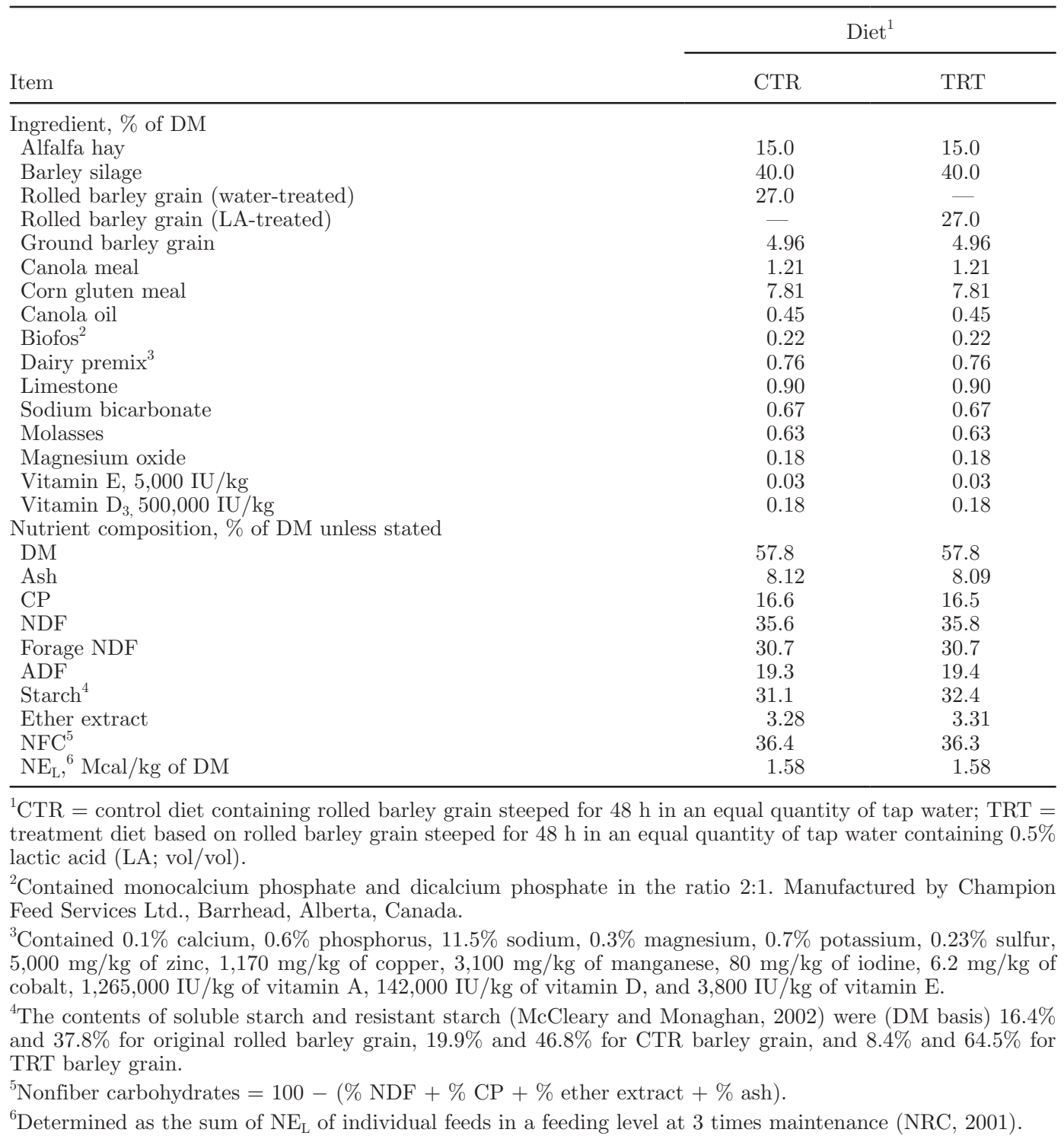

190, Molecular Devices Corporation, Sunnyvale, CA) at $585 \mathrm{~nm}$. The contents of $\mathrm{CP}, \mathrm{NDF}$, starch, and $\mathrm{NE}_{\mathrm{L}}$ were similar across diets. Ingredients and chemical composition of the diets are presented in Table 1.

\section{In Vivo Rumen Fermentation}

To evaluate the effects of treatment on in vivo rumen fermentation, the $\mathrm{pH}$ and VFA concentration in the rumen fluid were measured. For this, about $250 \mathrm{~mL}$ of the rumen fluid was collected on d 11, 13, 15, 17, and 21 of the experimental period shortly before the morning feeding. In addition, on the last day (i.e., d 21) of the experimental period, rumen fluid samples were taken every $2 \mathrm{~h}$ from 0800 until $2000 \mathrm{~h}$ to investigate the diurnal responses. Rumen fluid samples were collected in the ventral rumen sac through the cannula using a tube fitted with a strainer and syringe into a $140-\mathrm{mL}$ plastic container. Rumen fluid $\mathrm{pH}$ was measured by a mobile $\mathrm{pH}$ meter (Accumet AP61, Fischer Scientific, Ottawa, Ontario, Canada) immediately after sample collection. To evaluate the effect of treatment on the risk of SARA, the duration that rumen $\mathrm{pH}$ was $<5.8$ from 0 to $12 \mathrm{~h}$ post-feeding was also estimated assuming an exponential function of $\mathrm{pH}$ curve between 2 adjacent time points. For VFA analysis, about $100 \mathrm{~mL}$ of rumen fluid was centrifuged at $2,010 \times g$ for $20 \mathrm{~min}$ at $4^{\circ} \mathrm{C}$ (Rotanta $460 \mathrm{R}$, Hettich Zentrifugan, Tuttlingen, Germany) and 2 replicates of supernatant, $5 \mathrm{~mL}$ each, were stored at $-20^{\circ} \mathrm{C}$ until analyzed to determine VFA concentrations. Rumen VFA were separated and quantified using gas chromatography (Varian 3700, Varian Spe- 
cialties Ltd., Brockville, Ontario, Canada) using a 15-m (0.53-mm i.d.) fused silica column (DB-FFAP column; J\&W Scientific, Folsom, CA). Concentration of lactate in the rumen fluid supernatants was determined using commercially available lactate assay kits (Biomedical Research Service Center, Buffalo, NY). All samples were tested in duplicate and the lactate concentration was determined by reading the optical density values on a microplate spectrophotometer (Spectramax 190, Molecular Devices Corporation) at $492 \mathrm{~nm}$.

\section{In Situ Degradation Trial}

To evaluate the kinetics of DM degradation, duplicate samples of barley grain were used as substrates for incubation using a subset of 6 from the total 8 cows, and variables of its in situ DM disappearance were used as indices of degradation kinetics. In addition to the CTR substrate, rolled barley substrates steeped (in a ratio of 1 to $1, \mathrm{wt} / \mathrm{vol}$ ) in $0.5 \%$ or $1.0 \%$ LA (TRT1 and TRT2, respectively) were also incubated to test the effect of a higher concentration of LA on in situ degradation kinetics. To evaluate the effects of diet on degradation characteristics of the rumen, untreated (i.e., not steeped in water) rolled barley grain was incubated in the rumen of cows fed the CTR and TRT diets, and parameters of the in situ degradation kinetics were evaluated.

In both in situ trials, the total incubation time in the rumen was $72 \mathrm{~h}$. Samples of approximately $4 \mathrm{~g}$ of all substrates were dried at $60^{\circ} \mathrm{C}$ for $72 \mathrm{~h}$ and ground to pass through a 2-mm screen. Subsequently, the samples were transferred in Dacron polyester bags $(5 \times 10 \mathrm{~cm})$ with a pore size of $52 \pm 5 \mu \mathrm{m}$ (mean \pm SD) and incubated in duplicate in the rumen. The bags were soaked in warm water for $10 \mathrm{~min}$ before insertion into the rumen to simulate the saliva addition. Bags were placed in large mesh retaining sacs before being incubated and were then placed in the rumen for 0 (water-washed, but not incubated in the rumen), 2, 4, 8, 16, 24, 48, and $72 \mathrm{~h}$.

After removal from the rumen, bags were washed under cold, running tap water, machine washed using the procedure described by Cherney et al. (1990), and dried at $60^{\circ} \mathrm{C}$ for $48 \mathrm{~h}$. Variables of in situ kinetics of DM disappearance of the substrates were estimated using the NLIN procedure of SAS (SAS Institute, 2003) according to the following model (McDonald, 1981):

$$
Y=a+b \times\left(1-e^{k_{d}(t-L)}\right) \text { for } t>L,
$$

where $Y$ is the DM disappearance (\%) at a certain time after incubation; $a$ is the soluble fraction (\%); $b$ is the insoluble, potentially degradable fraction $(\%) ; k_{\mathrm{d}}$ is the fractional rate of disappearance $(\% / \mathrm{h}) ; L$ is the lag time (h); and $t$ is the time of incubation (h). The effective rumen degradability (ERD) was calculated assuming a fractional passage rate $\left(k_{\mathrm{s}}\right)$ of $6 \% / \mathrm{h}$ using the following equation:

$$
\mathrm{ERD}=a+b k_{\mathrm{d}} /\left(k_{\mathrm{d}}+k_{\mathrm{s}}\right) .
$$

\section{Feed Intake and Milk Composition}

Individual feed intake and milk production were recorded daily during the last $11 \mathrm{~d}$ of the measurements period. Feed intake was calculated as the difference between the total daily feed given to each cow and the total of the feed refusals the next morning. Milk samples were collected on $\mathrm{d} 1,7,9$, and 11 of the measurements period, at 0500 and $1500 \mathrm{~h}$, and were analyzed for milk fat, CP, MUN, SCC, and lactose contents by mid-infrared spectroscopy (MilkoScan 605, A/S N Foss Electric, Hillerød, Denmark) at Central Milk Testing Laboratory (Edmonton, Alberta, Canada). Daily milk energy output was estimated from measured milk yield and concentrations of milk fat, CP, and lactose according to the NRC (2001) equation:

$$
\begin{gathered}
\mathrm{NE}_{\mathrm{L}}(\mathrm{Mcal} / \mathrm{kg} \text { of milk })=0.0929 \times \text { fat } \%+0.0547 \\
\times \text { protein } \%+0.0395 \times \text { lactose } \% .
\end{gathered}
$$

The $\mathrm{NE}_{\mathrm{L}}$ intake was calculated from measured DMI and $\mathrm{NE}_{\mathrm{L}}$ content of the diets, whereby the latter was determined as the sum of $\mathrm{NE}_{\mathrm{L}}$ contents of individual feeds in a feeding level at 3 times maintenance (NRC, 2001). The ratio of $\mathrm{NE}_{\mathrm{L}}$ milk output: $\mathrm{NE}_{\mathrm{L}}$ intake was calculated to evaluate the effect of dietary treatment on milk energy efficiency.

\section{Statistical Analyses}

All data were analyzed using the MIXED procedure of SAS (SAS Institute, 2003). For each response variable tested, the model included the fixed effects of period, sequence, measurement time (i.e., day or hour), and treatment as well as the resulting 2-way interaction of the latter 2 factors. Cow within sequence was considered a random effect. Measurements collected at different times on the same cow were considered repeated measures in the ANOVA. The variance-covariance structure of the repeated measures was modeled separately for each response variable according to the lowest values of the fit statistics based on the Bayesian information criteria, and an appropriate structure was fitted. Degrees of freedom were approximated by 


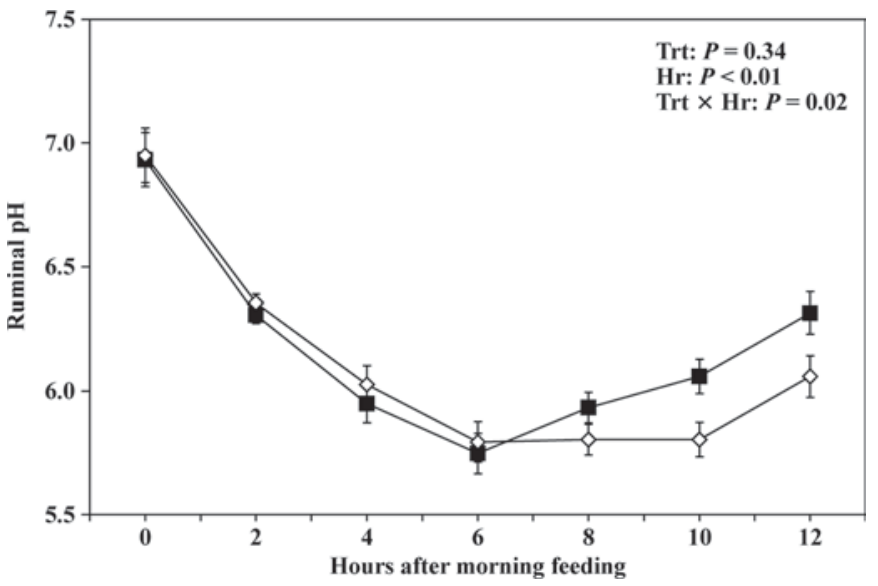

Figure 1. Diurnal variation of rumen $\mathrm{pH}$ in lactating Holstein cows fed diets based on rolled barley grain steeped in tap water $(\mathrm{CTR} ; \diamond)$ or in $0.5 \%$ lactic acid (TRT; $)$ solution $(\mathrm{LSM} \pm \mathrm{SEM} ; \mathrm{n}=8$; Trt $=$ effect of treatment; $\mathrm{Hr}=$ effect of sampling hour, Trt $\times \mathrm{Hr}=$ effect of treatment by sampling hour interaction).

the method of Kenward-Roger. Linear and quadratic effects of the treatment on in situ data were determined using the orthogonal contrasts. The PDIFF option was used in each of the comparisons. The least squares means and the respective standard error of the means were computed. Significance was declared at $P \leq 0.05$, whereas a tendency was considered up to $0.05<P \leq$ 0.10 . Because the effect of sequence was significant at $P<0.05$ for variables of milk production and composition, their baseline measurements taken just before starting of the experiment were used as covariates in the model of ANCOVA. Therefore, only data from the first period were used for their analysis as described recently by Shen (2006). Other features of the model regarding fixed and random effects were the same as explained for the ANOVA.
RESULTS

\section{Rumen Fermentation Profile}

Results showed a treatment by time interaction with regard to rumen $\mathrm{pH}$ (Figure 1). For example, compared with the CTR diet, cows fed the TRT diet had greater rumen $\mathrm{pH}$ starting at $8 \mathrm{~h}$ after the morning feeding and the difference became more pronounced at $10(P$ $=0.02)$ and $12 \mathrm{~h}(P=0.04)$ post-feeding. The latter effect was associated with a shorter duration that rumen $\mathrm{pH}$ was below 5.8 in cows fed the TRT $\operatorname{diet}(P=$ 0.04; Table 2).

Diurnal fluctuations related to concentration of total rumen VFA are reported in Figure 2, whereas molar percentages of individual VFA and concentration of lactate are presented in Table 2. Results showed an interaction between the diet and the hour of measurement for total VFA $(P=0.02$; Figure 2$)$. Thus, cows fed the CTR diet showed greater concentration of VFA particularly at 2 and $4 \mathrm{~h}$ post-feeding $(P=0.03$ and $P=0.01$, respectively). Diurnal data indicated that molar proportions of major VFA, including acetate and butyrate, in the rumen fluid were not affected by treatment $(P>0.05)$. Concentration of rumen lactate, measured every $2 \mathrm{~h}$ up to $12 \mathrm{~h}$ post-feeding, did not differ between the 2 groups (Table 2). In both groups of cows, the peak concentration of lactate was reached at $2 \mathrm{~h}$ post-feeding ( 1.25 vs. $1.31 \mathrm{mM}$ for CTR and TRT cows, respectively) and decreased thereafter. The pattern of rumen fermentation changed from acetate to butyrate production with time after the morning feeding, reaching a peak value at $6 \mathrm{~h}$ post-feeding, independent from the diet fed (data not shown). The diurnal patterns of all other VFA followed the same pattern as total VFA (Figure 2), indicating that the factor hour of

Table 2. Data of diurnal pH, proportions of VFA, and concentration of lactate in the rumen fluid of lactating cows fed 2 different diets

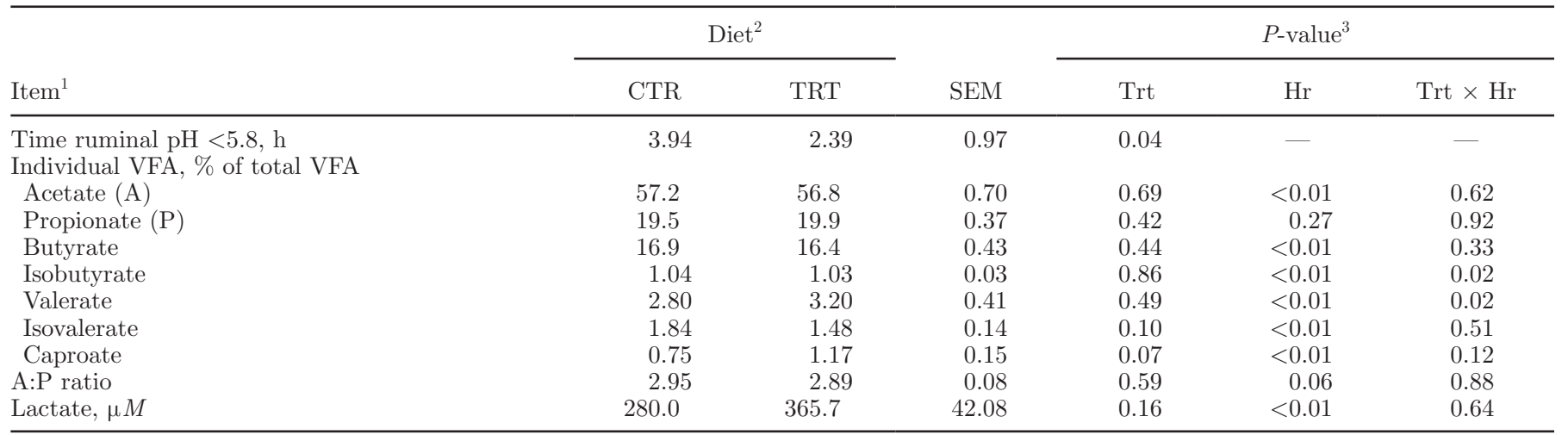

${ }^{1}$ Data of VFA and lactate are averaged across $0,2,4,8,10$, and $12 \mathrm{~h}$ post-feeding $(\mathrm{n}=8)$.

${ }^{2} \mathrm{CTR}=$ control diet containing rolled barley grain steeped for $48 \mathrm{~h}$ in an equal quantity of tap water; TRT $=$ treatment diet based on rolled barley grain steeped for $48 \mathrm{~h}$ in an equal quantity of tap water containing $0.5 \%$ lactic acid (vol/vol).

${ }^{3}$ Effect of dietary treatment (Trt), measurement hour $(\mathrm{Hr})$, and treatment by hour interaction (Trt $\times \mathrm{Hr}$ ). 


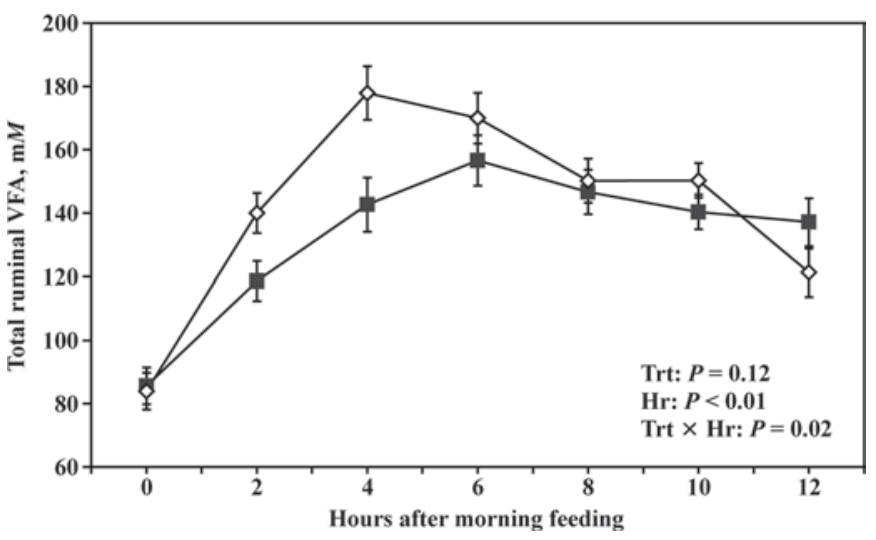

Figure 2. Diurnal variation of total VFA concentration in the rumen fluid of lactating Holstein cows fed diets based on rolled barley grain steeped in tap water $(\mathrm{CTR} ; \diamond)$ or in $0.5 \%$ lactic acid (TRT; solution $(\mathrm{LSM} \pm \mathrm{SEM} ; \mathrm{n}=8$; Trt $=$ effect of treatment; $\mathrm{Hr}=$ effect of sampling hour, Trt $\times \mathrm{Hr}=$ effect of treatment by sampling hour interaction).

measurement affected both concentrations and molar proportions of individual VFA during the time after the morning feeding.

Results of day-to-day variations indicated greater concentration of preprandial VFA in the rumen fluid of cows fed the CTR diet $(P<0.01$; Figure 3$)$. Also, the concentrations of total VFA were affected by the day of measurement $(P<0.01)$ and there was an interaction between the treatment and day of sampling on the total concentration of VFA $(P=0.03$; Figure 3$)$. Furthermore, the preprandial rumen fermentation data showed that cows fed the TRT diet had lower concentration of lactate in the rumen fluid $(P=0.01$; Table $3)$. Results also demonstrated that molar percentages of acetate decreased $(P=0.04)$, whereas those of propionate tended to increase $(P=0.09)$ when cows were fed the TRT diet. Diet alone or in combination with the sampling day did not have an effect on preprandial rumen $\mathrm{pH}$ in this study (Table 3 ).

\section{In Situ Rumen Digestion Kinetics}

Data showing the effects of feeding a CTR or TRT diet on rumen degradation characteristics of the substrate (i.e., untreated rolled barley grain) are shown in Table 4. Compared with the CTR diet, the rumen of the cows fed the TRT diet demonstrated greater lag time for substrate DM degradation $(P<0.01)$ and tended to decrease the fractional degradation rate as well as the potential degradability $(P=0.10$; Table 4$)$.

Data from the in situ trial showing the DM disappearance of rolled barley grain or rolled barley grained steeped in 2 different LA solutions are given in Table 5 . Results showed a quadratic effect of LA on the ERD of the substrates. Interestingly, the ERD decreased from
CTR to TRT1 but increased for TRT2 substrate $(P=$ $0.05)$. The potentially degradable DM fraction tended to be quadratically lower in TRT1 substrate compared with the other 2 substrates $(P=0.07)$. No effect of different substrate treatments on the potential degradability of the substrates $(P>0.05)$ was observed. In addition, the soluble fraction remained unaffected by different substrate treatments in the present study $(P$ $>0.05)$.

\section{DMI, Milk Production, and Composition}

Data for DMI, milk production, and milk composition are shown in Table 6 . Cows consumed approximately 16 to $18 \mathrm{~kg}$ of DM/d; however, DMI was not different between treatments. Actual milk yield, FCM, and ECM were not affected by treatment in this study. In addition, the percentages and daily yields of milk protein and lactose as well as concentrations of MUN and SCC were similar between the $2 \operatorname{diets}(P>0.05)$. However, cows fed the TRT diet increased milk fat content $(P$ $=0.04$; Table 6$)$. Similarly, the TRT diet tended to increase the fat:protein ratio in the milk $(P=0.10)$. Cows fed the TRT diet showed numerically higher milk fat yield, although the assumed tendency or significance levels were not reached $(P>0.10)$. Treatment did not affect energy intake, milk energy, or the ratio between energy milk output and energy intake in this study (Table 6).

\section{DISCUSSION}

Our study provided evidence that steeping barley grain in $0.5 \%$ LA improved rumen fermentation profile,

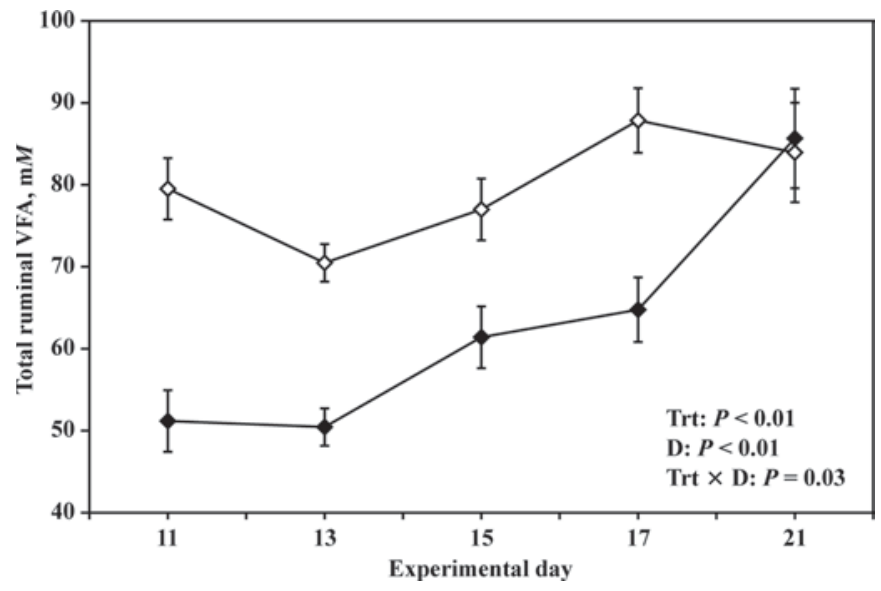

Figure 3. Day-to-day variation of total VFA concentration measured before feeding in rumen fluid of lactating Holstein cows fed rolled barley grain steeped in tap water $(\mathrm{CTR} ; \diamond)$ or in $0.5 \%$ lactic acid (TRT; - $)$ solution $(\mathrm{LSM} \pm \mathrm{SEM} ; \mathrm{n}=8$; Trt $=$ effect of treatment; $\mathrm{D}=$ effect of sampling day, Trt $\times \mathrm{D}=$ effect of treatment by sampling day interaction). 
Table 3. Day-to-day variation of preprandial ruminal $\mathrm{pH}$, proportions of VFA, and concentration of lactate in lactating cows fed 2 different diets

\begin{tabular}{|c|c|c|c|c|c|c|}
\hline Item $^{1}$ & \multicolumn{2}{|c|}{ Diet $^{2}$} & SEM & \multicolumn{3}{|c|}{$P$-value ${ }^{3}$} \\
\hline $\begin{array}{l}\text { Ruminal pH } \\
\text { Individual VFA. \% of total VFA }\end{array}$ & 7.06 & 7.05 & 0.03 & 0.91 & 0.03 & 0.78 \\
\hline Acetate $(\mathrm{A})$ & 67.0 & 63.9 & 0.97 & 0.04 & $<0.01$ & 0.01 \\
\hline Propionate $(\mathrm{P})$ & 18.8 & 21.4 & 1.03 & 0.09 & 0.08 & 0.11 \\
\hline Butyrate & 9.07 & 9.22 & 0.40 & 0.80 & 0.06 & 0.42 \\
\hline Isovalerate & 2.05 & 1.99 & 0.15 & 0.77 & 0.95 & 0.80 \\
\hline Caproate & 0.38 & 0.31 & 0.03 & 0.08 & 0.33 & $<0.01$ \\
\hline A:P ratio & 3.65 & 3.19 & 0.21 & 0.14 & 0.03 & 0.23 \\
\hline Lactate, $\mu M$ & 205.3 & 140.4 & 16.36 & 0.01 & 0.29 & $<0.01$ \\
\hline
\end{tabular}

${ }^{1}$ Samples were collected shortly before the morning feeding on $\mathrm{d} 11,13,15,17$, and 21 of each experimental period $(\mathrm{n}=8)$.

${ }^{2} \mathrm{CTR}=$ control diet containing rolled barley grain steeped for $48 \mathrm{~h}$ in an equal quantity of tap water; TRT $=$ treatment diet based on rolled barley grain steeped for $48 \mathrm{~h}$ in an equal quantity of tap water containing $0.5 \%$ lactic acid (vol/vol).

${ }^{3}$ Effect of dietary treatment (Trt), measurement day (D), and treatment by day interaction (Trt $\times$ D).

lowered the risk of SARA, and enhanced milk fat content in experimental cows. Results showed that cows fed the TRT diet maintained greater rumen fluid $\mathrm{pH}$ between 8 and $12 \mathrm{~h}$ post-feeding, the time when rumen $\mathrm{pH}$ in TMR-fed cows often reaches its nadir (Nordlund and Garrett, 1994). Furthermore, cows fed the LA-steeped barley grain diet had shorter time in which the rumen $\mathrm{pH}$ was below 5.8. Maintenance of rumen $\mathrm{pH}$ above 5.8 during the postprandial intensive fermentation phases is critical for the normal activity of rumen microbiota and prevention of SARA (Krause and Oetzel, 2006; Zebeli et al., 2008).

The mechanism by which LA treatment of barley grain maintained greater rumen $\mathrm{pH}$ values in the TRT group is not clear at present; however, it is speculated that modulation of starch characteristics might be one of the reasons. In support of this postulate are the re- sults of the chemical analyses of starch that showed that LA treatment decreased the content of soluble starch in the barley grain by $8 \%$ and increased that of resistant starch by $17.7 \%$. Soluble starch (i.e., carbohydrates) is rapidly degraded in the rumen, releasing large amounts of VFA, whereas resistant starch is partially degraded in the rumen and partially in the intestines, thereby contributing less VFA in the rumen fluid (Sutton, 1968). Indeed, our results showed that steeping barley grain in $0.5 \% \mathrm{LA}$ for $48 \mathrm{~h}$ before feeding to the cows lowered concentration of total VFA in the rumen fluid. Previous research, by our team and others, indicated that production and accumulation of VFA in the rumen of cows fed barley grain causes a rapid fall in rumen pH (Yang et al., 1997: Emmanuel et al., 2008). If VFA production rate surpasses its absorption and neutralization rates, particularly during the intensive

Table 4. The kinetics parameters of DM disappearance of substrate ${ }^{1}$ incubated for $72 \mathrm{~h}$ in the rumen of 6 lactating dairy cows fed 2 different diets

\begin{tabular}{|c|c|c|c|c|}
\hline \multirow[b]{2}{*}{ Parameter } & \multicolumn{2}{|c|}{ Diet $^{2}$} & \multirow[b]{2}{*}{ SEM } & \multirow[b]{2}{*}{$P$-value } \\
\hline & CTR & TRT & & \\
\hline Soluble fraction $(a), \%$ & 49.9 & 54.9 & 2.27 & 0.15 \\
\hline Degradable fraction $(b),{ }^{3} \%$ & 38.3 & 32.9 & 2.36 & 0.14 \\
\hline Fractional degradation rate $\left(k_{\mathrm{d}}\right), \% / \mathrm{h}$ & 9.2 & 7.3 & 0.76 & 0.10 \\
\hline Lag time, $\mathrm{h}$ & 6.17 & 9.33 & 0.41 & $<0.01$ \\
\hline $\mathrm{ERD},{ }^{4} \%$ & 72.9 & 72.5 & 1.64 & 0.86 \\
\hline Potential degradability, $\%$ & 88.2 & 87.9 & 0.87 & 0.10 \\
\hline \multicolumn{5}{|c|}{${ }^{1}$ The substrate incubated in duplicates in the Dacron bags consisted of untreated rolled barley grain. } \\
\hline \multicolumn{5}{|c|}{$\begin{array}{l}{ }^{2} \mathrm{CTR}=\text { control diet containing rolled barley grain steeped for } 48 \mathrm{~h} \text { in an equal quantity of tap water; TRT }= \\
\text { treatment diet based on rolled barley grain steeped for } 48 \mathrm{~h} \text { in an equal quantity of tap water containing } 0.5 \% \\
\text { lactic acid (vol/vol). } \\
{ }^{3} \text { Insoluble, potentially degradable fraction. } \\
{ }^{4} \text { Effective rumen degradability, calculated using ruminal fractional rate of passage }\left(k_{\mathrm{s}}\right) \text { of } 6 \% / \mathrm{h}(\mathrm{ERD}=a+ \\
b k_{\mathrm{d}} /\left(k_{\mathrm{d}}+k_{\mathrm{s}}\right) .\end{array}$} \\
\hline
\end{tabular}


Table 5. The kinetics parameters of DM disappearance of different substrates of rolled barley grain incubated with Dacron bags for $72 \mathrm{~h}$ in the rumen of 6 lactating dairy cows

\begin{tabular}{|c|c|c|c|c|c|c|}
\hline \multirow[b]{2}{*}{ Parameter } & \multicolumn{3}{|c|}{ Rolled barley substrates ${ }^{1}$} & \multirow[b]{2}{*}{ SEM } & \multicolumn{2}{|c|}{$P$-value } \\
\hline & CTR & TRT1 & TRT2 & & Linear & Quadratic \\
\hline Degradation rate $\left(k_{\mathrm{d}}\right),{ }^{3} \% / \mathrm{h}$ & 18.6 & 12.3 & 21.2 & 3.86 & 0.64 & 0.13 \\
\hline $\mathrm{ERD},{ }^{4} \%$ & 82.4 & 81.5 & 83.6 & 0.42 & 0.12 & 0.05 \\
\hline Potential degradability, $\%$ & 92.0 & 92.6 & 92.3 & 0.33 & 0.72 & 0.44 \\
\hline
\end{tabular}

${ }^{1}$ Rolled barley substrates steeped for $48 \mathrm{~h}$ before incubating in the rumen in an equal quantity of tap water (CTR) or in $0.5 \%$ (TRT1) or $1.0 \%$ (TRT2) lactic acid (vol/vol).

${ }^{2}$ Insoluble, potentially degradable fraction of DM.

${ }^{3}$ Fractional rate of disappearance of DM.

${ }^{4}$ Effective rumen degradability, calculated using ruminal fractional rate of passage $\left(k_{\mathrm{s}}\right)$ of $6 \% / \mathrm{h}\left(\mathrm{ERD}=a+b k_{\mathrm{d}} /\left(k_{\mathrm{d}}+k_{\mathrm{s}}\right)\right.$.

fermentation phases, and rumen $\mathrm{pH}$ remains below 5.8 for periods longer than 4 to $5 \mathrm{~h} / \mathrm{d}$, then the risk of developing SARA is high (Zebeli et al., 2008).

Another reason for greater rumen $\mathrm{pH}$ values in cows fed the TRT diet might be the greater utilization of lactate, possibly caused by an effect of LA-treated barley on the activity of lactate-utilizing bacteria. This hypothesis is supported by lower rumen lactate during the preprandial period in cows fed the TRT diet. Our results are consistent with recent findings in goats supplemented with disodium fumarate, another organic acid, that indicated an increased activity of lactate-utilizing bacteria and, as a result, a low lactate concentration and an increased rumen $\mathrm{pH}$ in the treated animals (Mao et al., 2008). Moreover, our results showed a tendency for the TRT diet to increase the molar proportion of propionate and decrease that of acetate in preprandial rumen fluid. It is known that propionate is derived from lactate through the reductive route, and utilization of acetate is necessary as a cofactor for conversion of lactate to propionate (Satter and Esdale, 1968).

Table 6. Data of DMI, milk production and composition, and production efficiency of lactating cows fed 2 different diets

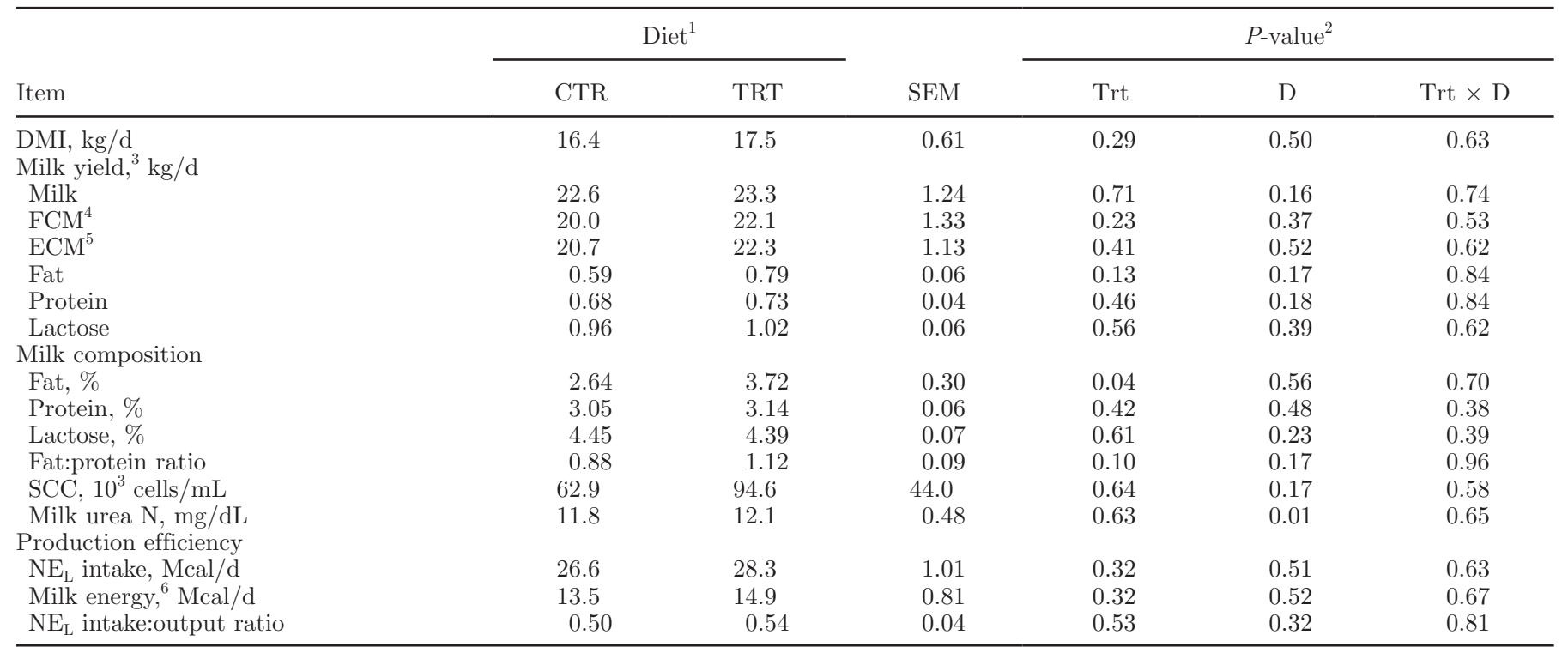

${ }^{1} \mathrm{CTR}=$ control diet containing rolled barley grain steeped for $48 \mathrm{~h}$ in an equal quantity of tap water; TRT = treatment diet based on rolled barley grain steeped for $48 \mathrm{~h}$ in an equal quantity of tap water containing $0.5 \%$ lactic acid (vol/vol).

${ }^{2}$ Effect of dietary treatment (Trt), measurement day (D), and treatment by day interaction (Trt $\times$ D).

${ }^{3}$ Data across $\mathrm{d} 11,17,19$, and 21 of the first experimental period $(\mathrm{n}=4)$.

${ }^{4} \mathrm{FCM}=$ milk amount $(\mathrm{kg}) \times(0.4255+16.425 \times \%$ fat $/ 100)$.

${ }^{5} \mathrm{ECM}=$ milk amount $(\mathrm{kg}) \times(0.327+7.2 \times \%$ protein $/ 100+12.96 \times \%$ fat $/ 100)$.

${ }^{6}$ Milk energy $(\mathrm{Mcal} / \mathrm{kg}$ of milk $)=0.0929 \times \%$ fat $+0.0547 \times \% \mathrm{CP}+0.0359 \times \%$ lactose. 
Results obtained from the in situ trial fully supported the in vivo findings. Accordingly, there was a prolonged degradation lag time of untreated rolled barley grain substrate incubated in the rumen of cows fed the TRT diet. There is evidence that lag time in the degradation of substrates rich in starch is crucial for the outcome of rumen fluid $\mathrm{pH}$. For example, Miller and Muntifering (1985) showed that the rapid decrease in rumen $\mathrm{pH}$ caused by feeding high-starch diets was related primarily to the diminution of diet degradation lag time in the rumen. Therefore, prolonged degradation lag time in this study might have contributed to the better rumen $\mathrm{pH}$ values observed in cows fed the LA-treated diet. Although the exact mechanism(s) by which LA treatment of barley grain lowers rumen degradability of starch is not clear at present, our data are in agreement with those reported by Östman et al. (2002) indicating lower hydrolysis index for cereal starch treated with LA.

Contrary to our expectations, the degradation rate of rolled barley grain treated with $1 \%$ LA was greater compared with the $0.5 \%$ LA-treatment during the in situ trial. Although rolled barley grain treated with $1.0 \%$ LA was tested only in situ, increased degradation rate by the latter treatment suggests the importance of LA concentration on degradation of barley grain in the rumen. Studies using corn starch have shown that steeping corn grain in LA improves the solubility and recovery of matrix proteins and starch granules (Perez et al., 2001). It is possible that the ability of LA to disperse the protein matrix and increase starch recovery rate becomes more significant with greater concentrations of LA in solution.

One of the most important findings of this study was the evidence of greater milk fat content in the group of cows fed the LA-treated diet. Because milk fat is related to the diet composition and metabolic processes in the rumen, this variable is often used as an indicator of rumen health and fiber adequacy in dairy cows (Zebeli et al., 2008). The positive effect of LA-treated diet on milk fat content may be related to improved rumen $\mathrm{pH}$ and a better environment for rumen microbiota in cows fed the TRT diet. Indeed, previous research indicates that rumen $\mathrm{pH}$ plays a key role with regard to milk fat content in dairy cows (Enjalbert et al., 2008). In addition, data from our team showed strong associations between rumen $\mathrm{pH}$ and the amount of rumen endotoxin, a cell wall component of gram-negative bacteria, with milk fat content (Zebeli and Ametaj, 2009). The latter data support the argument that maintenance of an optimal rumen $\mathrm{pH}$ by the LA-treated diet might have played a role in our results.

The lack of an effect of dietary treatment on DMI, milk production, and other variables of milk energy efficiency can be explained by the fact that cows in the present study were in late lactation, a period during which cows are less responsive to dietary treatments compared with early lactation. The absence of an effect of treatment on the yields and contents of milk protein and lactose is consistent with a previous report by Peterson et al. (2003), who also showed no differences on the same variables, although milk fat content was lowered during high-grain feeding.

\section{CONCLUSIONS}

Altogether, results of this study provided evidence that steeping rolled barley grain in $0.5 \%$ LA modulated rumen fermentation patterns, increased rumen $\mathrm{pH}$ during the most critical phases of rumen fermentation, and enhanced milk fat content in late-lactating Holstein cows fed a $45 \%$ barley grain-based concentrate diet. The results also suggested the potential utilization of LA-treated barley to decrease the risk of SARA and improve productivity when high proportions of barley grain are fed to lactating dairy cows. Because animals in our experiment were late-lactating cows and because at this stage of lactation cows generally are less responsive to dietary interventions, it would be of interest to test the effects of feeding LA-treated barley grain on early-lactating dairy cows as well as on cows of a greater production potential.

\section{ACKNOWLEDGMENTS}

We acknowledge the financial support of Alberta Milk (Edmonton, Alberta, Canada), Alberta Livestock Industry Development Fund (Edmonton, Alberta, Canada), and Natural Sciences and Engineering Research Council of Canada (Ottawa, Ontario, Canada). We are grateful to the technical staff at Dairy Research and Technology Center (University of Alberta, Edmonton, Canada) for their help and care of the cows.

\section{REFERENCES}

Ametaj, B. N., B. J. Bradford, G. Bobe, R. A. Nafikov, Y. Lu, J. W. Young, and D. C. Beitz. 2005. Strong relationships between mediators of the acute phase response and fatty liver in dairy cows. Can. J. Anim. Sci. 85:165-175.

AOAC. 2002. Official Methods of Analysis. Vol. 1. 17th ed., rev. 1. Association of Official Analytical Chemists, Arlington, VA.

Canadian Council on Animal Care. 1993. Guide to the Care and Use of Experimental Animals. Vol. 1. 2nd ed. CCAC, Ottawa, Ontario, Canada.

Cherney, D. J. R., J. A. Paterson, and R. P. Lemenager. 1990. Influence of in situ bag rinsing technique on determination of dry matter disappearance. J. Dairy Sci. 73:391-397.

Dehghan-Banadaky, M., R. Corbett, and M. Oba. 2007. Effects of barley grain processing on productivity of cattle. Anim. Feed Sci. Technol. 137:1-24.

Emmanuel, D. G. V., S. M. Dunn, and B. N. Ametaj. 2008. Feeding high proportions of barley grain stimulates an inflammatory response in dairy cows. J. Dairy Sci. 91:606-614. 
Enjalbert, F., Y. Videau, M. C. Nicot, and A. Troegeler-Meynadier. 2008. Effects of induced subacute ruminal acidosis on milk fat content and milk fatty acid profile. J. Anim. Physiol. Anim. Nutr. (Berl.) 92:284-291.

Krause, K. M., and G. R. Oetzel. 2006. Understanding and preventing ruminal acute acidosis in dairy herds: A review. Anim. Feed Sci. Technol. 126:215-236.

Liljeberg, H. G. M., C. H. Lonner, and I. M. E. Björck. 1995. Sourdough fermentation or addition of organic acids or corresponding salts to bread improves nutritional properties of starch in healthy humans. J. Nutr. 125:1503-1511.

Manzoni, M. S. J., S. N. Kronka, and J. F. Lopes-Filho. 2002. Effect of steeping conditions (sulphur dioxide, lactic acid, and temperature) on starch yield, starch quality, and germ quality from the intermittent milling and dynamic steeping process (IMDS) for a Brazilian corn hybrid. Cereal Chem. 74:633-638.

Mao, S. Y., G. Zhang, and W. Y. Zhu. 2008. Effect of disodium fumarate on ruminal metabolism and rumen bacterial communities as revealed by denaturing gradient gel electrophoresis analysis of 16 S ribosomal DNA. Anim. Feed Sci. Technol. 140:293-306.

McCleary, B. V., and D. A. Monaghan. 2002. Measurement of resistant starch. J. AOAC Int. 85:665-675.

McDonald, I. 1981. A revised model for the estimation of protein degradability in the rumen. J. Agric. Sci. 96:251-252.

Miller, B. G., and R. B. Muntifering. 1985. Effect of forage:concentrate on kinetics of forage fiber digestion in vivo. J. Dairy Sci. 68:4044.

Nocek, J. E. 1997. Bovine acidosis: Implications on laminitis. J. Dairy Sci. 80:1005-1028.

Nordlund, K. V., and E. F. Garrett. 1994. Rumenocentesis: A technique for collecting rumen fluid for the diagnosis of subacute rumen acidosis in dairy herds. Bovine Pract. 28:109-112.

NRC. 2001. Nutrient Requirements of Dairy Cattle. 7th rev. ed. Natl. Acad. Sci., Washington, DC.

Östman, E. M., M. Nilssont, H. G. M. Lilberg, G. Molin, and I. M. E. Björck. 2002. On the effect of lactic acid on blood glucose and insulin responses to cereal products: Mechanistic studies in healthy subjects and in vitro. J. Cereal Sci. 36:339-346.

Perez, O. E., M. Haros, and C. Suarez. 2001. Corn steeping: Influence of time and lactic acid on isolation and thermal properties of starch. J. Food Eng. 48:251-256.
Peterson, D. G., E. A. Matitashvili, and D. E. Bauman. 2003. Dietinduced milk fat depression in dairy cows results in increased trans-10, cis-12 CLA in milk fat and coordinate suppression of mRNA abundance for mammary enzymes involved in milk fat synthesis. J. Nutr. 133:3098-3102.

Rutgersson, A., V.-M. Toukkuri, P. Reinikainen, and H. Lingnert. 2000. Influence of hydrothermal treatment on lipid oxidation in barley. Cereal Chem. 77:407-413.

SAS Institute. 2003. SAS User's Guide: Statistics. Release 9.1.3. SAS Inst. Inc., Cary, NC.

Satter, L. D., and W. J. Esdale. 1968. In vitro lactate metabolism by ruminal ingesta. Appl. Microbiol. 16:680-688.

Shen, D. 2006. Estimate carryover effect in clinical trial crossover designs. In Proc. SAS Conf., PharmaSUG, May 21-24, Bonita Springs, FL.

Stone, W. C. 2004. Nutritional approaches to minimize subacute ruminal acidosis and laminitis in dairy cattle. J. Dairy Sci. 87(E Suppl.):E12-E26.

Sutton, J. D. 1968. The fermentation of soluble carbohydrates in rumen contents of cows fed diets containing a large proportion of hay. Br. J. Nutr. 22:689-712.

Van Soest, P. J., J. B. Robertson, and B. A. Lewis. 1991. Methods for dietary fiber, neutral detergent fiber, and nonstarch polysaccharide in relation to animal nutrition. J. Dairy Sci. 74:3583-3597.

Yang, W. Z., K. A. Beauchemin, K. Koenig, and L. M. Rode. 1997. Effects of barley, hulless barley, and corn in concentrates on site and extent of digestion by lactating cows. J. Dairy Sci. 80:28852895

Zebeli, Q., and B. N. Ametaj. 2009. Relationships between rumen lipopolysaccharide and mediators of inflammatory response with milk fat production and efficiency in dairy cows. J. Dairy Sci. 92:3800-3809.

Zebeli, Q., J. Dijkstra, M. Tafaj, H. Steingass, B. N. Ametaj, and W. Drochner. 2008. Modeling the adequacy of dietary fiber in dairy cows based on responses of ruminal $\mathrm{pH}$ and milk fat production to composition of the diet. J. Dairy Sci. 91:2046-2066. 